\title{
Endothelial Function and Mechanical Properties of the Common Carotid Artery in Children on Parenteral Nutrition
}

\author{
YACINE AGGOUN, VIRGINIE COLOMB, MAILA TURANLAHTI, ODILE CORRIOL, \\ OLIVIER GOULET, DANIEL SIDI, CLAUDE RICOUR, AND DAMIEN BONNET \\ INSERM 0016, Faculté de Médecine Necker-Enfants Malades, 75015 Paris, France [Y.A., M.T., D.S., \\ D.B.], and Service de Gastro-Entérologie et Nutrition Pédiatriques, Hôpital Necker-Enfants Malades, \\ 75015 Paris, France [V.C., O.C., O.G., C.R.]
}

\begin{abstract}
ABSTR
Intravenous administration of nutrition mixtures induces en-
dothelial damage and arterial wall remodeling in animal models.
To study endothelial function and common carotid artery me-
chanical properties in children receiving parenteral nutrition, we
used noninvasive ultrasonic measurements in 18 children on
parenteral nutrition and 18 controls. No difference appeared in
the geometry of the common carotid artery (intima media thick-
ness, systolic and diastolic diameters) between the patients on
parenteral nutrition and the controls. The incremental elastic
modulus was significantly higher in the patients on parenteral
nutrition (1.8 \pm 0.4 versus $1.4 \pm 0.54$ mm Hg $\left.\cdot 10^{3}, p<0.05\right)$
reflecting alteration of the elastic properties of the arterial wall
independent of the vessel geometry. The flow-mediated dilata-
tion of the brachial artery was significantly lower in the patients
on parenteral nutrition $(6 \pm 3$ versus $8 \pm 3 \%, p<0.05)$, whereas
the dilatation after glyceryl trinitrate administration was similar
\end{abstract}
In children, as in adults, total or complementary PN is a well-established intervention in acute or chronic illnesses that limit oral feeding, impair digestive function, and threaten nutritional status. In children with short bowel syndrome, inflammatory bowel diseases, or intractable diarrhea of infancy, PN provides normal growth and pubertal development (1). The endothelium injury of the pulmonary artery by administering nutrition admixtures into the atrium has been documented in experimental models (2). Another study depicted induction of early atherosclerosis with endothelial damage, and arterial wall remodeling has been induced in rats receiving lipid emulsions parenterally (3). Hitherto, however, the consequences of artificial nutrition on the mechanical properties of large arteries and on endothelium function in humans remain unknown.

Received October 24, 2001; accepted February 1, 2002

Correspondence: Damien Bonnet, M.D., Ph.D., Service de Cardiologie Pédiatrique, Hôpital Necker-Enfants Malades, 149, rue de Sèvres 75015 Paris, France; e-mail: damien.bonnet@nck.ap-hop-paris.fr

DOI: 10.1203/01.PDR.0000115680.46755.F5
(22 \pm 9 versus $25 \pm 9 \%$ ). Children on parenteral nutrition exhibit endothelial dysfunction and altered stiffness of the common carotid artery. The noninvasive methods used in this study may prove useful for objectively determining the effects of various preventive methods. (Pediatr Res 55: 789-793, 2004)
PN, parenteral nutrition
CCA, common carotid artery
DBP, diastolic blood pressure
DD, diastolic diameter
LCSA, lumen cross-sectional area
PP, pulse pressure
SBP, systolic blood pressure
SD, systolic diameter
WCSA, wall cross-sectional area

\section{Abbreviations}

We hypothesized that nutrient solutions administered directly into the bloodstream induce arterial changes, as has been shown in experimental studies in animals. Therefore, we sought to determine whether the endothelial function and stiffness of the common carotid artery were altered in children receiving long-term $\mathrm{PN}$.

\section{METHODS}

\section{Subjects}

The study population included 18 children on PN (5 girls and 13 boys). At the time of the study, the mean age was $10 \pm$ 3 y (range, 4.5-17 y). Digestive diseases were as follows: short bowel syndrome $(n=10,4$ of which were secondary to Hirschsprung's disease), chronic intestinal pseudo-obstruction $(n=5)$, and intractable diarrhea of infancy $(n=3)$. All patients were on home PN. Fourteen of 18 received also enteral nutrition. Cyclic PN was delivered over 10-14 h nightly. All patients but three depended on PN from birth. The mean PN duration was $10.1 \pm 3.9 \mathrm{y}$ (range, $4.5-17 \mathrm{y}$ ) and the patients 
received $5.4 \pm 1.4 \mathrm{PN}$ infusions per week (range, 3-7). Four patients depended on total PN and were potential candidates for small bowel transplantation. Two of them had liver fibrosis. Nevertheless, all the children had normal liver function and none had hyperbilirubinemia at the time of the study. At vascular examination, the nonprotein energy supply was $38 \pm$ $10 \mathrm{kcal} / \mathrm{kg} / \mathrm{d}$ (range, $18-56$ ) or $159 \mathrm{~kJ} / \mathrm{kg} / \mathrm{d}$, with a $25 \%$ mean lipid-to-total nonprotein energy ratio. The nonprotein energyto-nitrogen ratio was $173 \pm 32 \mathrm{kcal} / \mathrm{g}$ nitrogen. Energy, nitrogen, and mineral supplies had been regularly adjusted to the age, weight, and height to fulfil the specific needs of normal growth.

Until 1989, the only fat emulsion provided was Intralipid 20\% (Pharmacia, Saint-Quentin en Yvelines, France), including $100 \%$ soybean-derived long-chain triglycerides (LCT) with $60 \%$ polyunsaturated fatty acids. Medialipid 20\% (Braun Medical, Boulogne, France) including 50\% soybean-derived LCT plus $50 \%$ medium-chain triglycerides (MCT) has been used since 1989 in four children. Clinoleic (Baxter SA-Clintec, Maurepas, France) including $100 \%$ LCT with $80 \%$ olive oiland $20 \%$ soybean-derived polyunsaturated fatty acids has been used since 1999 in seven other children. At the time of study, fat emulsions used were Intralipid $20 \%$ in eight patients, Clinoleic $20 \%$ in six patients, and Medialipid $20 \%$ in the other four. Vitamin E was systematically added into lipid emulsions $(0.6 \mathrm{mg} / \mathrm{g} \mathrm{LCT})$. The rhythm of lipid delivery was $4.4 \pm 0.9$ d/wk (range, 3-6 days per week).

Control subjects were 18 healthy children (mean \pm SD age, $10 \pm 3 \mathrm{y}$ ). Control children were selected from our outpatient Department of Pediatric Cardiology among children evaluated for anorganic cardiac murmur. All were normotensive, had a normal ECG, and echocardiography. None of these control subjects had known vascular risk factors.

Our institutional review board approved the study and all parents gave written informed consent for the study.

\section{Measurements}

Blood pressure measurement. Brachial blood pressure was measured with an oscillometric method using a Dinamap (Critikon 8100, GE Medical Systems, Waukesha, WI, U.S.A.) after 10 min of recumbence. The PP was defined as the difference between SBP and DBP. All arterial measurements were performed at least $4 \mathrm{~h}$ after PN had been stopped. The examinations and all measurements (IMT and diameters of the CCA and of the brachial artery) were performed by the same investigator (Y.A.). Repeatability of measurements was assessed as previously described $(4,5)$.

Arterial measurements. Noninvasive arterial measurements were performed with a real-time B-mode ultrasound imager (Acuson Sequoia, Mountain View, CA, U.S.A.). The right CCA was examined with a 7-MHz vascular probe, according to a procedure previously described (4-7). The carotid artery was chosen to study the influence of PN on mechanical properties of the artery wall because this vessel is close to the heart and rich in elastic fibers. It is a representative site to evaluate the buffering function of the arterial system and is involved in the early stages of arterial stiffening. The average IMT obtained from the sample area represented the mean of at least 100 successive measurements of the distance between the two interfaces along $1.5 \mathrm{~cm}$ of artery. The mean of five IMT measures was used for calculation of mathematically derived parameters. The CCA diameters variations over at least five cardiac cycles as well as the synchronized ECG were visualized on the computer screen for visual agreement. The diastolic diameter was calculated as the mean of the minimal values of CCA lumen, corresponding to the $\mathrm{R}$ wave, for five consecutive cardiac cycles. In the same way, the systolic diameter was estimated as the mean of the maximal value of the CCA lumen during the same cardiac cycles.

Common carotid artery mechanical indexes. CCA compliance and CCA distensibility were determined according to the following formulas: $\mathrm{CCA}$ compliance $=\pi\left(\mathrm{SD}^{2}-\mathrm{DD}^{2}\right) / 4(\mathrm{PP})$ $\left(\mathrm{mm}^{2} \cdot \mathrm{mm} \mathrm{Hg}^{-1}\right)$; and CCA distensibility $=\left(\mathrm{SD}^{2}-\mathrm{DD}^{2}\right) /$ $\left(\mathrm{DD}^{2} \times \mathrm{PP}\right)\left(\mathrm{mm} \mathrm{Hg}^{-1} \cdot 10^{-2}\right)(8-10)$. Whereas distensibility provides information about "elasticity" of the artery as a hollow structure, the incremental elastic modulus (Einc, mm $\mathrm{Hg} \cdot 10^{3}$ ) provides information on the properties of the wall material, independent of its geometry. Einc $=[3(1+$ LCSA $/$ WCSA)]/CCA distensibility (10). CCA lumen cross-sectional area $\left(\right.$ LCSA, $\left.\mathrm{mm}^{2}\right)$ was calculated as LCSA $=\pi($ CCA diameter) ${ }^{2} / 4$. The wall cross-sectional area $\left(\mathrm{WCSA}, \mathrm{mm}^{2}\right.$ ) was calculated as $\mathrm{WCSA}=\pi(\mathrm{CCA} \text { diameter } / 2+\mathrm{IMT})^{2}-\pi(\mathrm{CCA}$ diameter $/ 2)^{2}$.

The CCA diastolic wall stress $\left(\mathrm{mm} \mathrm{Hg} \cdot 10^{2}\right)$ was calculated according to Lame's equation, WS $=\mathrm{DBP} \cdot(\mathrm{DD} / 2) / \mathrm{IMT}$, where IMT is intima-media thickness.

Assessment of endothelial function. After at least $30 \mathrm{~min}$ of rest, arterial endothelial and smooth muscle function was studied with a high-resolution vascular ultrasound system as described previously (11). Changes in arterial diameter in response to reactive hyperemia (increased flow producing endothelium-dependent vasodilatation) and to glyceryl trinitrate (endothelium-independent vasodilator) were measured. The target artery was scanned in longitudinal section (brachial artery $2-15 \mathrm{~cm}$ above the elbow), and the center of the vessel was identified when the clearest images of the anterior and posterior walls were obtained. The transmit zone was set to the level of the anterior vessel wall. Depth and gain settings were optimized to identify the lumen-to-vessel wall. Images were magnified with the resolution box function, leading to a television line width of approximately $0.065 \mathrm{~mm}$. Machine settings were kept constant during each study. Brachial diameters were measured at a fixed distance from an anatomic marker. The mean diameter was calculated from five cardiac cycles incident with the $\mathrm{R}$ wave on the ECG. Arterial flow velocity was measured by means of a pulsed Doppler signal at a $70^{\circ}$ angle to the vessel, with the range gate $(1.5 \mathrm{~mm})$ in the center of the artery. Flow increase was induced by inflation of a blood pressure cuff to $300 \mathrm{~mm} \mathrm{Hg}$. The cuff was released after $4 \mathrm{~min}$, and the artery was scanned for $30 \mathrm{~s}$ before and $90 \mathrm{~s}$ after cuff deflation, including a repeat flow velocity recording for the $15 \mathrm{~s}$ after cuff release. Ten minutes later, a resting scan was recorded. Glyceryl trinitrate (300 $\mu \mathrm{g}$ spray) was then administered sublingually, and the artery was scanned after $3 \mathrm{~min}$. 
Statistical analysis. Data were expressed as mean \pm SD. Variables that were not normally distributed were log transformed. Comparison between groups was performed by oneway ANOVA. Univariate linear regression analysis was performed on the data obtained from patients on PN to analyze the relationship between continuous variables. A value of $p<0.05$ was considered statistically significant.

\section{RESULTS}

The baseline demographic, hemodynamic, and biologic characteristics for PN patients and control subjects are summarized in Table 1. No differences in the anthropometric and hemodynamic parameters were found between the two groups. No significant difference was observed between the two groups for plasma levels of fasting triglycerides, total cholesterol, LDL cholesterol, and HDL cholesterol that were measured according to standard procedures.

Table 2 shows dimensions, mechanical properties of the CCA, and brachial artery reactivity in PN patients and controls. The intima-media thickness did not differ between the two groups $(0.49 \pm 0.03$ versus $0.50 \pm 0.02 \mathrm{~mm})$. The CCA diameter was not different between the two groups but the enlargement of CCA under the blood pressure was lower in the PN patients $(>32 \%, p<0.001)$. There was no difference in CCA compliance or distensibility between the two groups. The incremental elastic modulus of the CCA was higher in PN patients $(>28.5 \%, p<0.02)$. The wall stress was not different between the two groups.

There was no difference in resting diameters of the brachial artery in PN patients and controls ( $2.8 \pm 0.5$ versus $2.7 \pm 0.4)$. The flow-mediated dilatation at the brachial artery site was significantly lower in PN patients $(6 \pm 3$ versus $8 \pm 3 \%, p<$ $0.05)$. Conversely, the response to glyceryl trinitrate was similar in PN patients and in control subjects $(22 \pm 9$ versus $25 \pm$ $9 \%, \mathrm{NS})$.

In univariate analysis, no correlation was observed between plasma lipid level and flow-mediated dilatation in PN subjects. No correlation was found between the quality of the emulsion at the time of the study and the flow-mediated dilatation or the

Table 1. Characteristics of parenteral nutrition patients and control subjects

\begin{tabular}{lccc}
\hline \multicolumn{1}{c}{ Variables } & $\begin{array}{c}\text { Parenteral } \\
\text { nutrition } n=18\end{array}$ & $\begin{array}{c}\text { Controls } \\
n=18\end{array}$ & $p$ Value \\
\hline Age $(\mathrm{y})$ & $10 \pm 3$ & $10 \pm 3$ & 0.93 \\
Weight $(\mathrm{kg})$ & $30 \pm 10$ & $32 \pm 15$ & 0.65 \\
Height $(\mathrm{m})$ & $1.30 \pm 0.20$ & $1.33 \pm 0.20$ & 0.50 \\
Body surface area $\left(\mathrm{m}^{2}\right)$ & $1.08 \pm 0.30$ & $1.08 \pm 0.30$ & 0.93 \\
Body mass index $\left(\mathrm{kg} / \mathrm{m}^{2}\right)$ & $18 \pm 3$ & $17 \pm 4$ & 0.82 \\
Heart rate $(\mathrm{bpm})$ & $93 \pm 16$ & $82 \pm 17$ & 0.23 \\
Systolic pressure $(\mathrm{mm} \mathrm{Hg})$ & $106 \pm 8$ & $108 \pm 10$ & 0.52 \\
Diastolic pressure $(\mathrm{mm} \mathrm{Hg})$ & $58 \pm 10$ & $55 \pm 8$ & 0.29 \\
Pulse pressure $(\mathrm{mm} \mathrm{Hg})$ & $48 \pm 10$ & $53 \pm 7$ & 0.10 \\
Mean pressure $(\mathrm{mm} \mathrm{Hg})$ & $76 \pm 10$ & $74 \pm 10$ & 0.63 \\
Cholesterol $(\mathrm{mmol} / \mathrm{L})$ & $2.5 \pm 0.75$ & $2.7 \pm 0.32$ & 0.87 \\
HDL-C $(\mathrm{mmol} / \mathrm{L})$ & $1 \pm 0.58$ & $0.9 \pm 0.14$ & 0.88 \\
LDL-C $(\mathrm{mmol} / \mathrm{L})$ & $1.0 \pm 0.41$ & $1.03 \pm 0.23$ & 0.90 \\
Triglycerides $(\mathrm{mmol} / \mathrm{L})$ & $1.0 \pm 0.62$ & $1.36 \pm 0.23$ & 0.78 \\
\hline
\end{tabular}

Values shown are mean $\pm \mathrm{SD}$. incremental elastic modulus. Furthermore, no correlation appeared between the duration of the PN and the arterial alterations.

\section{DISCUSSION}

To our knowledge, our study using a noninvasive method is the first designed to investigate the repercussions of $\mathrm{PN}$ on structure and function of arteries in children. It shows an increase in the CCA stiffness associated with an impairment of the endothelium function. Several lines of evidence have demonstrated that atherosclerosis has its roots in childhood (12). Studies in animal models added credence to the fact that infusion of lipid emulsions or high concentrations of dextrose induce vascular changes $(2,3)$. The exact mechanisms through which PN might accelerate the formation of atheromatous lesion is unclear. The deleterious results of PN on endothelial function and on CCA stiffness that we observed could reflect the additive role of lipid infusion and hyperinsulinemia.

Complex interactions between the endothelial cell surface, macrophages, and smooth muscle cells lead to the formation of layers of fibrous tissue and cholesterol leading to mature atheromata. Diet-induced hypercholesterolemia is the most common model of nondenuding endothelial injury, closely resembling human spontaneous atherosclerosis (13). The relationship between dyslipidemia and vascular endothelium has been well established, not only in adults but also in children (4, 14). Experimental studies in healthy adults have shown a relationship between infusion of triglycerides and endothelial reactivity $(15,16)$. The quality of lipid emulsion infused in terms of fatty acid chain length and the proportion of unsaturated fatty acids is also of major concern. However, our results do not allow us to differentiate the respective effects of each emulsion. The metabolism of the oxidized fraction of lipids delivered via the parenteral route is relatively well known (17). On the other hand, the destiny of the nonoxidized fraction, which is caught by the reticulo-endothelial system, is far less described. Chronic administration of lipid emulsions might overload reticulo-endothelial cells and induce their acute or chronic activation (18). Additionally, a recent study showed that injection of triglycerides (10\% Intralipid) activated arterial expression of nuclear factor (NF)- $\kappa \mathrm{B}$ to the same extent as injection of VLDL. These results suggested that VLDL may promote the development of atherosclerotic lesions by activation of the proinflammatory transcription factor NF- $\kappa$ B. The effect appeared to be mediated by a release of VLDL fatty acids but not to involve VLDL oxidation (19). Further, accumulation of monocyte-derived foam cells in focal areas of the arterial intima, a key step in early atherogenesis, is mediated by expression of monocyte adhesion molecules by the endothelium. Indeed, vascular cell adhesion molecule-1 (VCAM-1) is induced in rabbit aortic endothelium in vivo within $1 \mathrm{wk}$ after initiation of an atherogenic diet (20). Finally, peroxidation of exogenous lipids can stimulate leukocyte adhesion through a superoxide-dependent step and induce endothelial injury (21, 22). The above-mentioned mechanisms might be involved in the genesis of arterial dysfunction in children on PN with lipid emulsions. We are aware that the transverse design of our 
Table 2. Dimensions, mechanical properties of the common carotid artery, and brachial artery reactivity in parenteral nutrition patients and controls

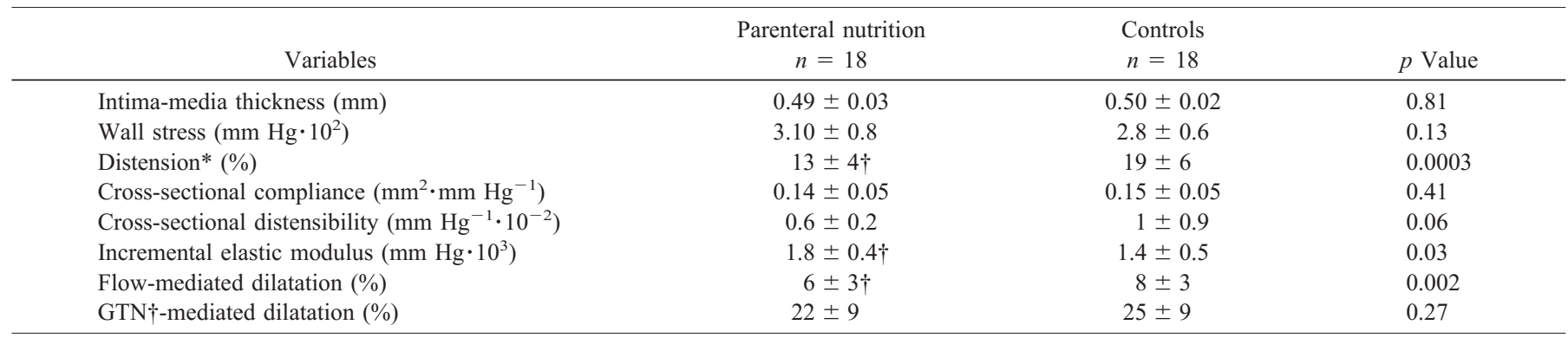

Values shown are mean $\pm \mathrm{SD}$. SD, systolic diameter; DD, diastolic diameter; GTN, glycerylnitrate.

$*$ Distension $=\mathrm{SD}-\mathrm{DD} / \mathrm{DD}$.

$\dagger p<0.05$ vs control.

study does not allow us to address the potential impact of lipids infusion or impaired glucose metabolism at length.

Endothelium dysfunction might also be related to hyperinsulinemia that has been described in experimental long-term PN studies. Glucose perfusion has been shown to stimulate insulin secretion (23). Further, in rats receiving continuous PN, plasma FFA were significantly increased as well as some amino acids that have been shown to be potent insulin secretagogues (24). In humans, however, few data are available regarding the effects of long-term $\mathrm{PN}$ on insulin secretion and sensitivity. In patients who depend on long-term parenteral support, cyclic nocturnal PN provides usually 2- to 5-fold the daily glucose hepatic production over a $10-14 \mathrm{~h}$ period. In these patients, hyperinsulinemia or increased peptide-C levels have been reported $(25,26)$. Insulin resistance has also been shown in rats receiving continuous PN who presented with marked hyperinsulinemia in spite of the absence of hyperglycemia (24). Human studies have also suggested that substrate competition during PN can lead to insulin resistance (27). The route of nutrient delivery may also act on insulin sensitivity through the release of gut hormones. It has been suggested that after an oral meal, plasma contain one or several factor(s) like GIP and GLP-1 that increase tissue sensitivity to insulin (28). It is of note that the insulin resistance syndrome, with its components hyperinsulinemia, obesity, hypertension, and hyperlipidemia, has been recognized as a major precursor of atherosclerotic cardiovascular disease in adults $(29,30)$. However, the mechanisms of insulin-related endothelium dysfunction remain controversial.

The endothelium controls both smooth muscle tone and vascular wall remodeling. It has been demonstrated that basal NO production influences large-artery distensibility $(31,32)$. This may explain why conditions that exhibit endothelial dysfunction are also associated with increased arterial stiffness. In our PN patients, the vascular dysfunction may be due to the combination of chronic and acute effects of nutrients infusion on the endothelium. As we are studying young patients, we may speculate that the remodeling of the arterial wall is incipient as we did not observe increased IMT. Longitudinal studies are needed to determine whether the changes that we observed in PN patients have implications for the late development of atherosclerosis.
Endothelial dysfunction and increased arterial stiffness may be induced in the course of PN in different ways. First, by the duration of parenteral infusion, despite the absence of correlation between the abnormalities described and the duration of PN in our study. Second, the daily regular and cyclic PN is responsible for variations of substrates and hormonal plasma concentrations inducing regular metabolic injury on the vascular system over the day, which likely contribute to the endothelium dysfunction. The glucose should be considered because recent trials have underscored the importance of elevated glucose levels as an independent risk factor (33). Further, elevated glucose level increased endothelial cell permeability in large vessels, leading to interstitial edema, and may enhance cell proliferation and matrix production (34).

The evaluation of vascular functions in patients on prolonged PN showed signs of preclinical cardiovascular risk factors. The respective roles of lipid infusion and of insulin resistance as major determinants of endothelium impairment due to PN have to be clarified. A long-term follow-up of the patients included in the current study has been planned whatever the course of the underlying disease. The follow-up will focus on the evolution of arterial disorders, especially to assess their reversibility after the return to enteral nutrition or their worsening with time in patients who remain dependent on PN. The physiologic abnormalities in children on PN shown by using noninvasive methods provide a marker that may enable objective assessment of the effects of various preventive methods.

\section{REFERENCES}

1. Ricour C, Gorski AM, Goulet O, De Potter S, Corriol O, Postaire M, Niihoul-fekete C, Jan D, Révillon Y, Lortat-Jacob S, Pellerin D 1990 Home parenteral nutrition in children: 8 years of experience with 112 patients. Clin Nutr 9:65-71

2. Kawarasaki H, Fujiwara T, Fonkalsrud EW 1985 The effects of administering hyperalimentation solutions into the atrium and pulmonary artery. J Pediatr Surg 20:205-210

3. Saladino CF, Klein RA, Jonas EA 1987 Induction of early atherosclerosis in rats using parenterally-administered lipid emulsions. Artery14:304-315

4. Aggoun Y, Bonnet D, Sidi D, Girardet JP, Brucker E, Polak M, Safar ME, Levy BI 2000 Arterial mechanical changes in children with familial hypercholesterolemia. Atherioscler Thromb Vasc Biol 20:2070-2075

5. Aggoun Y, Sidi D, Levy BI, Lyonnet S, Kachaner J, Bonnet D 2000 Mechanical properties of the common carotid artery in Williams syndrome. Heart 84:290-293

6. Gariepy J, Massonneau M, Levenson J, Heudes D, Simon A 1993 Evidence for in vivo carotid and femoral wall thickening in human hypertension: groupe de prévention cardiovasculaire en médecine du travail hypertension. Hypertension 22:111-118 
7. Tounian P, Aggoun Y, Dubern B, Varille V, Guy-Grand B, Sidi D, Girardet JP, Bonnet D 2001 Presence of increased stiffness of the common carotid artery and endothelial dysfunction in severely obese children: a prospective study. Lancet 358:1400-1404

8. Boutouyrie P, Laurent S, Girerd X, Benetos A, Lacolley P, Abergel E, Safar M 1995 Common carotid artery stiffness and pattern of left ventricular hypertrophy in hypertensive patients. Hypertension 25:651-659

9. Benetos A, Laurent S, Hoeks AP, Boutouyrie P, Safar ME 1993 Arterial alteration with aging and high blood pressure. A noninvasive study of carotid and femoral artery. Arterioscler Thromb Vasc Biol 13:90-97

10. Hoeks APG, Brands PJ, Smeets GAM, Reneman RS 1990 Assessment of the distensibility of superficial arteries. Ultrasound Med Biol 16:121-128

11. Celermajer DS, Sorensen KE, Gooch VM, Spiegelhalter DJ, Miller OI, Sullivan ID 1992 Non-invasive detection of endothelial dysfunction in children and adults at risk of atherosclerosis. Lancet 340:1111-1115

12. Pathobiological Determinants of Atherosclerosis in Youths (PDAY) Research Group 1993 Natural history of aortic and coronary atherosclerotic lesions in youth: findings from the PDAY study. Arterioscler Thromb Vasc Biol 13:1291-1298

13. Simonsen U, Prieto D, Mulvany MJ, Ehrnrooth E, Korsgaard N, Nyborg NC 1992 Effect of induced hypercholesterolemia in rabbits on functional responses of isolated large proximal and small distal coronary arteries. Arterioscler Thromb Vasc Bio $12: 380-392$

14. Sorensen KE, Celermajer DS, Georgapoulos D, Hatcher G, Betteridge DJ, Deanfield JE 1994 Impairment of endothelium-dependent dilatation is an early event in children with familial hypercholesterolaemia and is related to the Lp (a) level. J Clin Invest 93:50-55

15. Lundman P, Eriksson M, Schenck-Gustafsson K, Karpe F, Tornvall P 1997 Transien triglyceridemia decreases vascular reactivity in young, healthy men without risk factors for coronary heart disease. Circulation 96:3266-3268

16. Steinberg HO, Tarshoby M, Monestel R, Hook G, Cronin J, Johnson A, Bayazeed B Baron AD 1997 Elevated circulating free fatty acid levels impair endotheliumdependent vasodilation. J Clin Invest 100:1230-1239

17. Bresson JL, Narcy P, Putet G, Ricour C, Sachs C, Rey J 1989 Energy substrate utilization in infants receiving total parenteral nutrition with different glucose to fat ratios. Pediatr Res 25:645-648

18. Goulet O, Girot R, Maier-Redelsperger M, Bougle D, Virelizier JL, Ricour C 1986 Hematologic disorders following prolonged use of intravenous fat in children. JPEN J Parenter Enteral Nutr 10:284-288

19. Dichtl W, Nilsson L, Goncalves I, Ares MP, Banfi C, Calara F, Hamsten A, Eriksson P, Nilsson J 1999 Very low-density lipoprotein activates nuclear factor-kappaB in endothelial cells. Circ Res 84:1085-1094
20. Li H, Cybulsky MI, Gimbrone MA, Libby P 1993 An atherogenic diet rapidly induces VCAM-1, a cytokine regulated mononuclear leucocyte adhesion molecule in rabbit aortic endothelium. Arterioscler Thromb Vasc Biol 13:197-204

21. Pironi L, Ruggeri E, Zolezzi C, Savarino L, Incasa E, Belluzzi A, Munarini A, Piazzi S, Tolomelli M, Pizzoferrato A, Miglioli M 1998 Lipid peroxidation and antioxidant status in adults receiving lipid-based home parenteral nutrition. Am J Clin Nutr 68:888-893

22. Lehr HA, Becker M, Marklund SL, Hubner C, Arfors KE, Kohlschutter A, Messmer K 1992 Superoxide-dependent stimulation of leukocyte adhesion by oxidatively modified LDL in vivo. Arterioscler Thromb Vasc Biol 12:824-829

23. Ward W, Halter J, Beard J, Porte D 1984 Adaptation of B and A cell function during prolonged glucose infusion in human subjects. Am J Physiol 246:E405-E411

24. Colomb V, Leturque A, Guihot G, Loizeau M, Lavie S, Colomer S, Ricour C, Girard J 1995 Route of nutrient delivery affects insulin sensitivity and liver glucose transporter expression in rat. Am J Physiol 269:E827-E833

25. Halter WJ, Beard J, Porte D 1984 Adaptation of B and A cell function during prolonged glucose infusion in human subjects. Am J Physiol 246:E405-E411

26. Wood RJ, Bengoa JM, Rosenberg IH 1985 Urinary C-peptide measurements in patients receiving continuous and cyclic total parenteral nutrition. J Lab Clin Med 105:259-264

27. Vigili de Kreutzenberg S, Lisato G, Riccio A, Giunta F, Bonato R, Petolillo M, Tiengo A, Del Prato S 1988 Metabolic control during total parenteral nutrition: use of an artificial endocrine pancreas. Metabolism 37:510-513

28. D'Alessio D, Kahn S, Leusner C, Ensinck J 1994 Glucagon-like peptide1 enhances glucose tolerance both by stimulation of insulin release and by increasing insulinindependent glucose disposal. J Clin Invest 93:2263-2266

29. Steinberg HO, Chaker H, Leaming R, Johnson A, Brechtel G, Baron A 1996 Obesity/insulin resistance is associated with endothelial dysfunction: implications for the syndrome of insulin resistance. J Clin Invest 97:2601-2610

30. Steinberger J 2001 Insulin resistance and cardiovascular risk in the pediatric patient Prog Pediatr Cardiol 12:169-175

31. Wilkinson IB, Qasem A, McEniery CM, Webb DJ, Avolio AP, Cockcroft JR 2002 Nitric oxide regulates local arterial distensibility in vivo. Circulation 105:213-217

32. Kinlay S, Creager MA, Fukumoto M, Hikita H, Fang JC, Selwyn AP, Ganz P 2001 Endothelium-derived nitric oxide regulates arterial elasticity in human arteries in vivo. Hypertension 38:1049-1053

33. Mäkimattila S, Virkamäki A, Groop $\mathrm{Ph}$, Cockcroft J, Utriainen $\mathrm{T}$, Fagerrudd J, Yki-Järvinen H 1996 Chronic hyperglycemia impairs endothelial function and insulin sensitivity via different mechanisms in insulin-dependent diabetes mellitus. Circulation 94:1276-1282

34. Nannipieri M, Rizzo L, Rapuano A, Pilo A, Penno G, Nalesi R 1995 Increased transcapillary escape rate of albumin in microalbuminuric type II diabetes patients. Diabetes Care 18:1-9 